\title{
Regulation of behavioral response to stress by microRNA-690
}

\author{
Jungyoung Park, Joonhee Lee, Koeul Choi and Hyo Jung Kang* (D)
}

\begin{abstract}
Psychiatric disorders are affected by genetic susceptibility and environmental adversities. Therefore, the regulation of gene expression under certain environments, such as stress, is a key issue in psychiatric disorders. MicroRNAs (miRNAs) have been implicated as post-transcriptional regulators of several biological processes, which can be differentially controlled through the targeting of multiple mRNAs. However, studies reporting the functions of miRNAs in relation to stress are lacking. In this study, we identified a significant increase in the expression of miRNA-690 (miR-690) in the medial prefrontal cortex (mPFC) of FK506-binding protein 51 knock-out (Fkbp5 KO) mice. In addition, the expression pattern of miR-690 was similar to the sucrose preference of the same group in WT and Fkbp5 KO mice. miR-690 was injected into the mPFC using a recombinant adeno-associated virus mediated gene delivery method. After recovery, miR-690 overexpressing mice were exposed to restraint stress for 2 weeks. In the sucrose preference test and forced swim test, the stressed miR-690 overexpressing mice showed higher sucrose preference and lower immobility time, respectively, than stressed mice injected with the control virus. In the novel object recognition test, the stressed miR-690 overexpressing mice interacted longer with the novel object than those injected with the control virus. These results showed that miR-690 might play a role in stress resilience and could provide new insights into the epigenetic regulation of stress-associated biological functions and diseases, such as depression and posttraumatic stress disorder.
\end{abstract}

Keywords: Fkbp5, MicroRNA, Medial prefrontal cortex, Stress

Stress is a state in which homeostasis cannot be maintained, and both physical and psychological stressors have been reported to cause alterations in the endocrine system [1]. One of the major endocrine systems associated with stress response is the hypothalamic-pituitaryadrenal (HPA) axis, which comprises the hypothalamus, pituitary gland, and adrenal gland [2]. The hypothalamus releases corticotropin-releasing hormone upon exposure to stress, which stimulates the anterior pituitary gland to release adrenocorticotropic hormone (ACTH). ACTH stimulates the adrenal cortex to produce glucocorticoids [2]. FK506-binding protein 51 (FKBP5), a co-chaperone

*Correspondence: hyokang@cau.ac.kr

Department of Life Science, Chung-Ang University, 84 Heukseok-ro, Dongjak-gu, Seoul 06974, South Korea of heat shock protein 90 (Hsp90), acts as a regulator of the HPA axis. FKBP5 also interacts with Hsp90 to interfere with glucocorticoid receptor-mediated signaling [3, 4]. In our previous study, we found that $F k b p 5$ knock-out (KO) mice exhibited significantly reduced depressive-like behaviors when exposed to stress, and transcriptomic analysis showed a distinct expression module associated with stress resilience in the medial prefrontal cortex (mPFC) [5]. The mPFC has been considered an important region associated with stress responses because it connects to several brain regions, such as the amygdala and hypothalamus, which regulate neuroendocrine and autonomic functions and mediate circuit-specific effects of stress on neuronal remodeling [6].

Over the past few years, epigenetics has been considered in the pathophysiology of many stress-related original author(s) and the source, provide a link to the Creative Commons licence, and indicate if changes were made. The images or other third party material in this article are included in the article's Creative Commons licence, unless indicated otherwise in a credit line to the material. If material is not included in the article's Creative Commons licence and your intended use is not permitted by statutory regulation or exceeds the permitted use, you will need to obtain permission directly from the copyright holder. To view a copy of this licence, visit http://creativecommons.org/licenses/by/4.0/. The Creative Commons Public Domain Dedication waiver (http://creativeco mmons.org/publicdomain/zero/1.0/) applies to the data made available in this article, unless otherwise stated in a credit line to the data. 
psychiatric disorders. Epigenetic modifications regulate gene expression without changing the original genetic code [7]. In particular, microRNAs (miRNAs) are highly expressed in the central nervous system and play important roles in the development of neural structures and the regulation of gene expression [8]. In addition, abnormal expression of miRNAs can lead to several neuropsychiatric disorders [9]. Therefore, elucidating the role of miRNAs can provide clues toward determining the mechanisms underlying these disorders. However, epigenetic regulation of miRNAs has not yet been fully investigated.

We conducted small RNA sequencing (RNA-seq) analysis to explore key miRNAs in the mPFC associated with stress, using Fkbp5 KO mice, with wild-type (WT) mice as controls (Additional file 1). In the Fkbp5 KO mice, which showed significantly lower $F k b p 5$ expression levels $(P<0.0001$, Additional file 3: Fig. S1), the expression levels of 41 miRNAs were altered, of which, 18 were upregulated and 23 were downregulated. Among the upregulated genes, the expression of microRNA-690 (miR-690) was significantly increased (fold change $=2.5128$, adjusted $P=3.5 \times 10^{-3}$ ) (Fig. 1a and Additional file 2: Table S1). Studies have reported that miR-690 plays roles in myeloid cell, osteogenic, and induced pluripotent stem cell differentiation and in the renin-angiotensin system [10-13]; however, the effects of miR-690 on stress response are unknown. We hypothesized that miR-690 could mediate the stress response. Therefore, to verify this hypothesis, miR-690 levels of Fkbp5 KO mice were assessed when subjected to restraint stress for 3 weeks [5]. Restraint stress, a widely used animal model of stress, can alter neurotransmission and gene regulation in the short term and can cause neuronal structure modifications over the long term [14]. The effect of the restraint stress was confirmed by the sucrose preference test (SPT), and the miR690 expression level was verified by quantitative PCR on total RNA extracted from the mPFC. The stressed WT (WT_ST) mice showed lower sucrose preference $\left(P=1.20 \times 10^{-3}\right)($ Additional file 3: Fig. S2) and a lower level of miR-690 expression than the WT control (WT $\mathrm{CT})$ mice $\left(P=2.80 \times 10^{-3}\right)$ (Fig. 1b). On the other hand, stressed KO (KO_ST) mice, which showed significantly reduced depressive-like behavior $\left(P=1.10 \times 10^{-3}\right)$ (Additional file 3: Fig. S2), exhibited upregulated expression of miR-690 compared with WT_ST mice $\left(P=3.00 \times 10^{-4}\right)$ (Fig. 1b).
We next infused either a control green fluorescent protein (GFP)-tagged recombinant adeno-associated virus (rAAV) or a viral construct containing miR-690 (rAAVGFP-miR-690) into the pre-limbic cortices of the mPFC of mice to evaluate the effects of miR-690 on behavioral responses induced by chronic restraint stress (Fig. 1c and Additional file 3: Fig. S3). After 2 weeks of recovery, mice were subjected to restraint stress for 2 weeks. Effects of stress and the influence of miR-690 expression were verified by the SPT, forced swim test, and novel object recognition test (NOR), which are established models to assess mouse behavior (Fig. 1d). In the absence of stress, there was no significant influence on mice behavior by miR-690 expression itself; however, the effects appeared when the mice were exposed to stressful conditions. Mice injected with the control virus (rAAV-GFP) showed significantly lower sucrose preference $\left(P=3.50 \times 10^{-3}\right)$, increased total immobility time $\left(P=2.60 \times 10^{-3}\right)$ and decreased interaction rate with a novel object $\left(P=3.40 \times 10^{-3}\right)$ following restraint stress for 2 weeks; however, anhedonia, despair, and cognitive dysfunction caused by stress were blocked by overexpression of miR-690 in the mPFC (Fig. 1e-g and Additional file 3: Fig. S4). Furthermore, we tested whether the overexpression of miR-690 in the $\mathrm{mPFC}$ is associated with anxiety using another stress paradigm, conditioned fear stress combined with singleprolonged stress $(\mathrm{CF}+\mathrm{SPS})$. In the elevated plus maze test, overexpression of miR-690 did not prevent anxiety caused by CF + SPS (Fig. 1h). Although more detailed verification is required, miR-690 overexpression does not seem to have a significant effect on stress-induced anxiety. However, compared to the control virus, miR690 overexpression tends to alleviate anxiety somewhat by overexpression itself, although not statistically significant.

In this study, we suggest that miR-690 could prevent depressive-like behaviors and cognitive dysfunction following exposure to restraint stress. Although further and more elaborate behavioral and molecular studies are necessary to identify the precise role of miR-690 in stress biology, our results demonstrated that miR-690 may be an epigenetic regulator of behavioral responses induced by chronic restraint stress. Because miRNAs can target multiple mRNAs and regulate their expression, determining the exact roles of miRNAs is essential. Therefore, additional studies associated with miR-690 and putative target genes will contribute toward providing therapeutic interventions for stress-related disorders. 


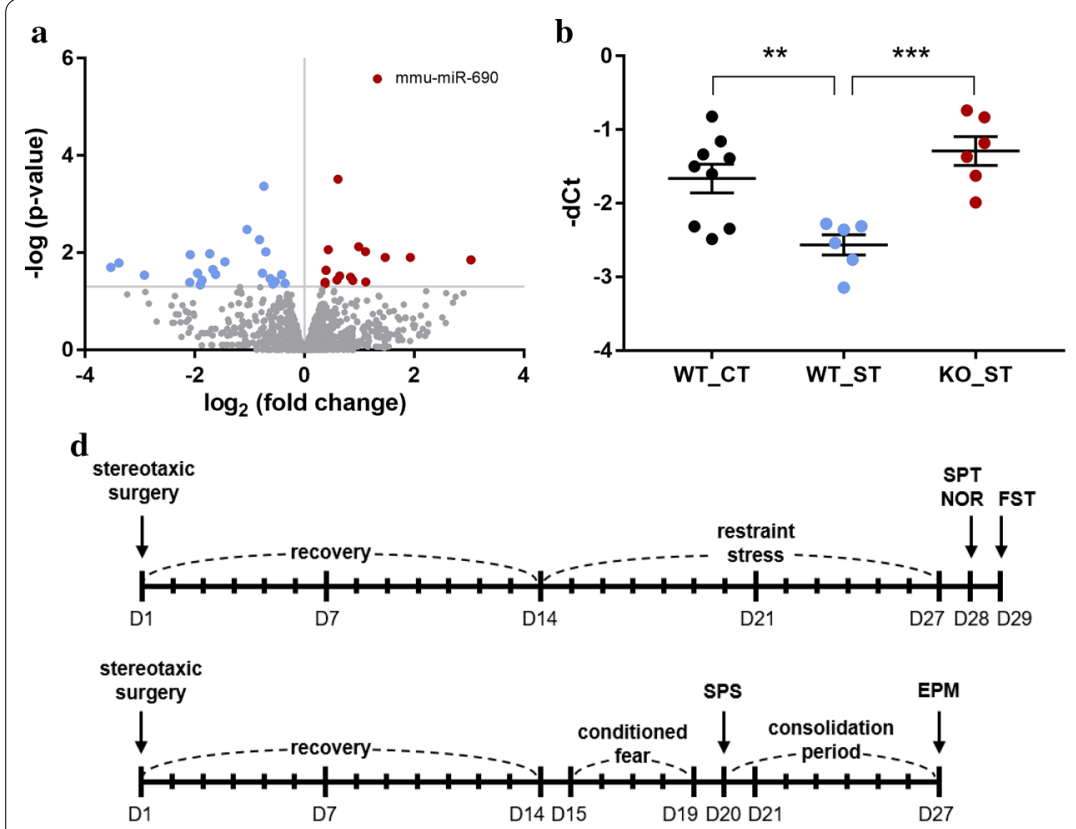

c

AAV-mir690

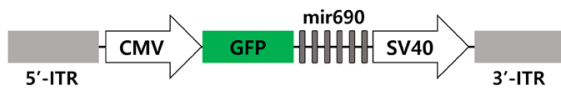

AAV-Control

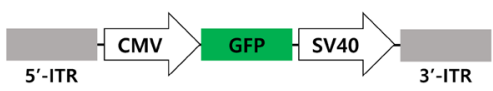

e Sucrose Preference Test
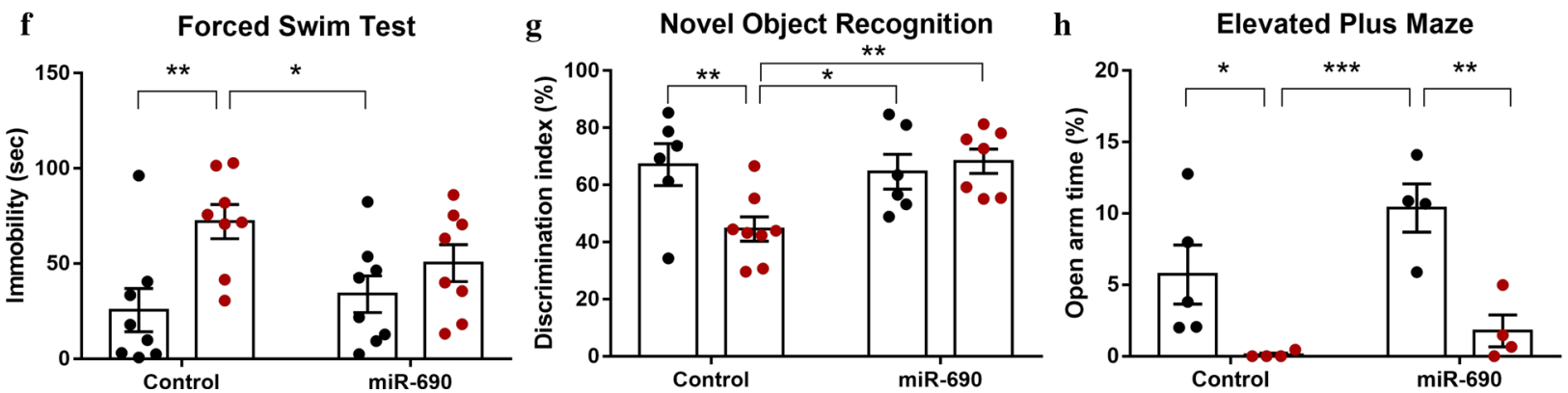

Fig. 1 Overexpression of miR-690 in the mPFC led to stress-resilient behaviors following restraint stress in mice. a Volcano plot representing the differentially expressed miRNAs in the mPFC of Fkbp5 KO mice, satisfying the criterion of $P$ value $<0.05$. Significantly altered miRNAs are indicated by blue (downregulated) and red (upregulated) dots. b The expression of mmu-miR-690 in the mPFC of mice subjected to the restraint stress. WT control mice (WT_CT, $n=9$ ); stressed WT mice (WT_ST, $n=6$ ); stressed Fkbp5 KO mice (KO_ST, $n=6)$. One-way ANOVA (F $[2$, $\left.18]=10.65, P=9.00 \times 10^{-4}\right)$; Fisher's LSD $\left.{ }^{* *} P<0.01,{ }^{* *} P<0.001\right)$. c AAV-miR-690 and AAV-control vector design; ITR inverted terminal repeat, CMV cytomegalovirus; GFP green fluorescent protein, SV40 simian virus 40. d Schematic timeline of experimental procedures and behavioral tests. Restraint stress (above) and conditioned fear stress combined with single-prolonged stress (CF +SPS) (below). e- $\mathbf{g}$ Influence of overexpression of miR-690 in the mPFC on mouse behavior following restraint stress. Results of sucrose preference test (e). Non-stressed control mice $(n=5)$; stressed control mice $(n=8)$; non-stressed miR-690 mice $(n=5)$; stressed miR-690 mice $(n=8)$. Two-way ANOVA (stress $\times$ virus, $F[1,22]=10.39$, $\left.P=3.90 \times 10^{-3}\right)$; Fisher's LSD $\left({ }^{* *} P<0.01\right)$. Results of forced swim test $(\mathbf{f})$. Non-stressed control mice $(n=8)$; stressed control mice $(n=8)$; non-stressed miR-690 mice $(n=8)$; stressed miR-690 mice $(n=8)$. Two-way ANOVA (stress, F $\left.[1,28]=9.97, P=3.80 \times 10^{-3}\right)$; Fisher's LSD $\left({ }^{*} P<0.05,{ }^{* *} P<0.01\right)$. Results of novel object recognition test $(\mathbf{g})$. Non-stressed control mice $(n=6)$; stressed control mice $(n=8)$; non-stressed miR-690 mice $(n=6)$; stressed miR-690 mice $(n=7)$. Two-way ANOVA (stress $\times$ virus, $\left.F[1,23]=5.81, P=2.44 \times 10^{-2}\right)$; Fisher's LSD $(* P<0.05, * * P<0.01)$. h Effects of CF + SPS and miR-690 on elevated plus maze test. Non-stressed control mice $(n=5)$; stressed control mice $(n=4)$; non-stressed miR-690 mice $(n=4)$; stressed miR-690 mice $(n=4)$. Two-way ANOVA (stress, F $\left.[1,13]=20.45, P=6.0 \times 10^{-4}\right)$; Fisher's LSD $\left({ }^{*} P<0.05,{ }^{* *} P<0.01,{ }^{* * *} P<0.001\right)$. In all data, black dots and red dots indicate non-stressed mice and stressed mice, respectively. Bars represent group mean and error bars represent SEM

\section{Supplementary Information}

The online version contains supplementary material available at https://doi. org/10.1186/s13041-021-00728-3.
Additional file 1. Materials and methods.

Additional file 2: Table S1. Normalized count values of differentially expressed microRNAs (miRNAs) in Fkbp5 knock-out (KO) mice 
Additional file 3: Figure S1. Fkbp5 expression level in the medial prefrontal cortex (mPFC) of Fkbp5 knock-out (KO) mice. Figure S2. Effects of Fkbp5 deletion and restraint stress on depressive-like behavior. Figure S3. The expression level of miR-690 after AAV-mediated gene transfer into the mPFC of mice. Figure $\mathbf{S} \mathbf{4}$. Novel and familiar objects interaction time in the novel object recognition test.

\section{Abbreviations}

ACTH: Adrenocorticotropic hormone; CF + SPS: Conditioned fear stress combined with single-prolonged stress; Fkbp5: FK506-binding protein 5; GFP: Green fluorescent protein; HPA axis: Hypothalamic-pituitary-adrenal axis; Hsp90: Heat shock protein 90; KO: Knock-out; KO_ST: Stressed KO; miRNA: MicroRNA; mPFC: Medial prefrontal cortex; NOR: Novel object recognition; rAAV: Recombinant adeno-associated virus; RNA-seq: RNA sequencing; SPT: Sucrose preference test; WT:Wild-type;WT_CT:WT control;WT_ST: Stressed WT.

\section{Acknowledgements \\ Not applicable}

\section{Authors' contributions}

JP performed most of the experiments including the animal behavior experiments and wrote the original draft of the manuscript. JL was involved in the acquisition of animal behavior data, and KC performed the molecular experiments. HJK designed the study and edited the manuscript. All authors read and approved the final manuscript.

\section{Funding}

This research was supported by the National Research Foundation of Korea (NRF) grant funded by the Ministry of Science and ICT (NRF2015M3C7A1031395, 2018M3C7A1024150) and by the Chung-Ang University Graduate Research Scholarship in 2019.

\section{Availability of data and materials}

The small RNA-seq raw data reported in this paper have been submitted to the Gene Expression Omnibus repository under the accession number (GSE139502).

\section{Ethics approval and consent to participate}

The animal experiments were conducted in accordance with the Chung-Ang University Council Directive for the use and care of laboratory animals, and the National Institutes of Health animal care guidelines. The Institutional Animal Care and Use Committee of Chung-Ang University approved all protocols described in this study.

\section{Consent for publication}

Not applicable.

\section{Competing interests}

The authors declare that they have no competing interests.

Received: 5 September 2020 Accepted: 1 January 2021 Published online: 09 January 2021

\section{References}

1. Chrousos GP, Gold PW. The concepts of stress and stress system disorders: overview of physical and behavioral homeostasis. JAMA. 1992;267:1244-52.

2. Shea A, Walsh C, Macmillan H, Steiner M. Child maltreatment and HPA axis dysregulation: relationship to major depressive disorder and post traumatic stress disorder in females. Psychoneuroendocrinology. 2005;30:162-78.

3. Binder EB, Bradley RG, Liu W, Epstein MP, Deveau TC, Mercer KB, et al. Association of FKBP5 polymorphisms and childhood abuse with risk of posttraumatic stress disorder symptoms in adults. JAMA. 2008;299:1291-305.

4. Hartmann J, Wagner KV, Liebl C, Scharf SH, Wang XD, Wolf M, et al. The involvement of FK506-binding protein 51 (FKBP5) in the behavioral and neuroendocrine effects of chronic social defeat stress. Neuropharmacology. 2012;62:332-9.

5. Kwon J, Kim YJ, Choi K, Seol S, Kang HJ. Identification of stress resilience module by weighted gene co-expression network analysis in Fkbp5deficient mice. Mol Brain. 2019;12:99.

6. Stanton $\mathrm{CH}$, Holmes AJ, Chang SWC, Joormann J. From stress to anhedonia: molecular processes through functional circuits. Trends Neurosci. 2019;42:23-42.

7. Peschansky VJ, Wahlestedt C. Non-coding RNAs as direct and indirect modulators of epigenetic regulation. Epigenetics. 2014;9:3-12.

8. Smalheiser NR, Lugli G, Rizavi HS, Torvik VI, Turecki G, Dwivedi Y. MicroRNA expression is down-regulated and reorganized in prefrontal cortex of depressed suicide subjects. PLoS ONE. 2012;7:e33201.

9. Zhou J, Nagarkatti P, Zhong Y, Ginsberg JP, Singh NP, Zhang J, et al. Dysregulation in microRNA expression is associated with alterations in immune functions in combat veterans with post-traumatic stress disorder. PLOS ONE. 2014;9:e94075.

10. Hegde VL, Tomar S, Jackson A, Rao R, Yang X, Singh UP, et al. Distinct microRNA expression profile and targeted biological pathways in functional myeloid-derived suppressor cells induced by $\triangle 9$-tetrahydrocannabinol in vivo: regulation of CCAAT/enhancer-binding protein alpha by microRNA-690. J Biol Chem. 2013;288:36810-26.

11. Yu S, Geng Q, Pan Q, Liu Z, Ding S, Xiang Q, et al. MiR-690, a Runx2targeted miRNA, regulates osteogenic differentiation of C2C12 myogenic progenitor cells by targeting NF-kappaB p65. Cell Biosci. 2016;6:10.

12. Xu Y, Huang $Y$, Guo $Y$, Xiong $Y$, Zhu S, Xu L, et al. microRNA-690 regulates induced pluripotent stem cells (iPSCs) differentiation into insulin-producing cells by targeting Sox9. Stem Cell Res Ther. 2019;10:59.

13. Menikdiwela KR, Ramalingam L, Abbas MM, Bensmail H, Scoggin S, Kalupahana NS, et al. Role of microRNA 690 in mediating Angiotensin II effects on inflammation and endoplasmic reticulum stress. Cells. 2020;9:1327.

14. Rinaldi A, Vincenti S, De Vito F, Bozzoni I, Oliverio A, Presutti C, et al. Stress induces region specific alterations in microRNAs expression in mice. Behav Brain Res. 2010;208:265-9.

\section{Publisher's Note}

Springer Nature remains neutral with regard to jurisdictional claims in published maps and institutional affiliations.

Ready to submit your research? Choose BMC and benefit from:

- fast, convenient online submission

- thorough peer review by experienced researchers in your field

- rapid publication on acceptance

- support for research data, including large and complex data types

- gold Open Access which fosters wider collaboration and increased citations

- maximum visibility for your research: over $100 \mathrm{M}$ website views per year

At BMC, research is always in progress.

Learn more biomedcentral.com/submissions 